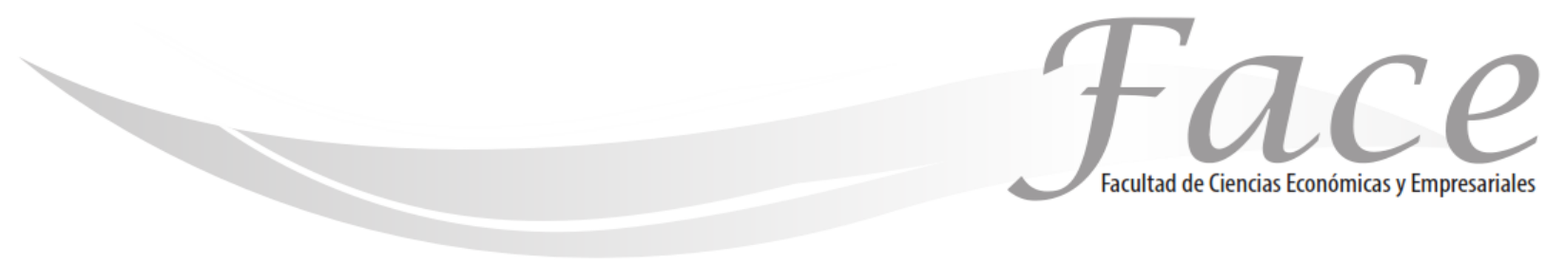

ISSN 1794-9920

Volumen $15-2$

Año 2015

Págs. $67-87$

\title{
UN ACERCAMIENTO TEÓRICO-PRÁCTICO A LA APLICACIÓN DEL PROCESO ADMINISTRATIVO EN LAS MIPYMES COLOMBIANAS *
}

Fecha de Recepción: 9 de Octubre 2015

Fecha de Aprobación: 20 de Diciembre 2015

\author{
Yenny Naranjo Tuesta * \\ ohemí Sánchez Villamil **
}

\section{Resumen:}

Al hacer referencia de la administración de las Mipymes muchas veces se tiene la idea que funcionan sin una estructura organizacional y administrativa definida; por ello, este documento presenta un análisis sobre el manejo administrativo en tres empresas colombianas pertenecientes al sector publicitario, con el fin de mostrar que es un factor fundamental para alcanzar la eficiencia y la eficacia organizacional. El documento retoma aspectos teóricos de los neoclásicos de la administración, para explicar y entender el proceso administrativo precisando sobre el desempeño organizacional y las laborales gerenciales. En ese sentido, para cumplir con lo propuesto, se maneja un enfoque cualitativo en la investigación que se soporta en entrevistas semi-estructuradas realizadas a los altos cargos en las tres Mipymes. Finalmente, se constata la parte teórica y el "hacer" o desarrollo administrativo de las compañías objeto de estudio, evidenciando las falencias que tienen administrativamente que perjudican su eficiencia organizacional, el crecimiento empresarial y la consolidación en el mercado.

Palabras Claves: Proceso administrativo, Mipymes colombianas, sector de servicios publicitarios, practica administrativa.

\footnotetext{
* Docente tiempo Completo de Contaduría Pública de la Faculta de Ciencias Administrativas y Contables de la Universidad de la Salle. Magister en Administración y Contaduría Pública de la Universidad Nacional de Colombia. Contacto: yenaranjo@unisalle.edu.co

** Estudiante de Contaduría Pública. Universidad de la Gran Colombia. Integrante de Semillero ICOLDI (Investigación Contable en Logística difusa). Contacto: dnsanchezv@gmail.com
} 


\title{
A THEORETICAL-PRACTICAL APPROACH TO THE APPLICATION OF THE ADMINISTRATIVE PROCESS IN COLOMBIAN MSMES
}

\begin{abstract}
:
When referring to the administration of MSMEs it is often thought that it functions without a well-defined organizational and administrative structure, therefore, this document provides an analysis of the administrative management of three Colombian companies in the advertising industry, in order to demonstrate that it is a key factor in achieving organizational effectiveness and efficiency. This paper reviews the neo-classical approach on management so as to explain and understand the administrative process of management responsibilities and organizational performance. The research was based on a qualitative approach and semi-structured interviews with the three MSMEs senior management and results show the companies administrative weaknesses and their effect on organizational efficiency, business growth and market consolidation.
\end{abstract}

Keywords: Administrative process, Colombian MSMEs, Advertising Industry, Administrative practice

\section{UMA ABORDAGEM TEÓRICO-PRÁTICA PARA A APLICAÇÃO DO PROCESSO ADMINISTRATIVO EM MPMES COLOMBIANAS}

\begin{abstract}
Resumo:
Fazendo referência a administração das MPMEs existe a ideia de que funcionam sem uma estrutura organizacional e administrativa definida, consequentemente este documento apresenta uma análise da gestão administrativa em três empresas colombianas pertencentes ao setor publicitário, com a finalidade de identificar os fatores fundamentais para alcançar a eficiência e eficácia organizacional. 0 documento retoma os aspectos teóricos da administração neoclássica, para explicar e entender 0 processo administrativo, especificando o desempenho gerencial e organizacional. Nesse sentido, a pesquisa se baseou em entrevistas semi-estruturadas realizadas com os funcionários de alto nível das três MPMEs. Finalmente, se evidencia as deficiências administrativas que têm as empresas estudadas dos quais prejudica sua eficiência organizacional, crescimento empresarial e consolidação no mercado.
\end{abstract}

Palavras-Chave: Processo Administrativo, MPMEs Colombianas, Setor Serviços Publicitários, Práticas Administrativas. 


\section{INTRODUCCIÓN:}

La administración y el papel del administrador ha sido estudiado por muchos años, estos aspectos fundamentan la teoría administrativa o la teoría organizacional. Cada teórico desde su percepción y punto de vista genera indicios sobre las organizaciones, el administrador y demás aspectos tanto internos como externos que influyen en el desempeño y el enfoque empresarial. El proceso administrativo por ello, no ha sido ajeno ni a estudios ni a cambios desde la perspectiva teórica desde los tradicionalistas o clásicos hasta los estructuralistas, neoclásicos 0 sistémicos cambian lo que se entiende 0 percibe como el deber ser en las organizaciones. Aunque no existe una fórmula secreta para conseguir el éxito empresarial, si es algo que por mucho tiempo se ha ido analizando.

Las empresas dependiendo de su tamaño y configuración establecen prioridades a la hora de desarrollar diariamente sus operaciones y establecer sus estrategias para mantenerse en el mercado. Sin embargo, las Mipymes presentan problemas a nivel organizacional frente a la eficiencia y eficacia administrativa, lo cual dificultad su desarrollo y crecimiento. Así mismo, éstas no se logran adaptarse fácilmente a los contextos cambiantes que el mercado establece, por ende, tienen a desaparecer fácilmente en el mercado. Se considera fundamental el papel del administrador en el crecimiento organizacional como en la aplicación del proceso administrativo, ya que es el quien consolida el camino a seguir y ejecutar en las empresas y quien proyecta las metas a cumplir no sólo en el día a día sino en el largo plazo.

Por esta razón, este trabajo se realizó para analizar la aplicación del proceso administrativo en tres Mipymes del sector de servicios publicitario; con el fin de establecer cómo se maneja y representa en la realidad la práctica descrita por la teoría neoclásica de la administración en las Mipymes colombianas. Para ello, se realizaron una serie de entrevistas a personas involucradas en los niveles directivos de estas empresas, permitiendo así, conocer la aplicación de la planeación, la organización, la dirección y el control desde una perspectiva interna de la empresa.

Por lo tanto, para cumplir con el objetivo propuesto se presenta el marco teórico, el cual es una relación de las diversas definiciones de algunos teóricos frente a lo que integra el proceso administrativo, el cual define a su vez las variables a estudiar en las empresas, luego se describe brevemente las políticas para el desarrollo de las Mipymes en Colombia, y un breve recuento del sector de servicios publicitarios. Con ello, se realiza la descripción de las empresas analizadas para describir en cada una de ellas el desempeño y la ejecución de las funciones del proceso administrativo. Todo esto, permitió concluir que la administración es una herramienta fundamental en el éxito de las empresas de este sector y de no tenerse en cuenta como aspecto de mejora en el mediano plazo pueden desaparecer del mercado, corroborando la hipótesis principal, en la cual el administrador no sólo debe tener conocimientos teóricos que fundamenten su labor sino que debe proyectar a la empresa a un largo plazo con metas claras y estrategias solidas que lo permitan consolidarse y mantenerse más allá de las ganancias diarias o de la priorización de utilidades a costa de una estructura organizacional.

Planteamiento del problema.

Con los constantes cambios del mundo repercutiendo en las organizaciones de hoy, es necesario entender la administración como factor esencial para poder cumplir con los objetivos. Los teóricos neoclásicos establecen las funciones del administrador en cuatro ejes fundamentales de acción como lo son: planear, organizar, dirigir y controlar; lo teórico debe permear la práctica y el hacer de los gestores organizacionales, por ende, se debe aplicar esto a todo tipo de organización: micro, medianas, pequeñas y grandes empresas; para dar solidez al funcionamiento, continuidad al desarrollo económico y social de las mismas.

Por ello, resulta incierto saber si las empresas de hoy (siglo XXI) aplican este proceso en el desarrollo de las actividades, como también conocer e identificar que tan eficaces y eficientes son frente al contexto, y si es funcional como mecanismo de adaptación a las tendencias del mercado. Por esta razón, este documento aborda dicha problemática desde el análisis de tres empresas del sector de servicios publicitarios, bajo la siguiente pregunta: ¿Es realmente aplicado y desarrollado el proceso administrativo bajo los conceptos descritos por los autores neoclásicos de la administración, en las empresas analizadas del sector de servicios, como un elemento esencial y fundamental para alcanzar la eficacia y la eficiencia organizacional?

\section{MARCO TEÓRICO:}

\section{El proceso administrativo.}

Dentro de las características principales de la teoría neoclásica de la administración, se encuentra: el desarrollo del papel administrativo en las organizaciones, la preocupación de los principios generales de la misma, el 
énfasis tanto en los objetivos como en los resultados y la consolidación del proceso administrativo.

Existe un gran número de autores neoclásicos que abordan los aspectos instrumentales de la práctica administrativa, haciendo una re-estructuración y una re-afirmación a los postulados clásicos propuestos por Frederick Winslow Taylor y Henry Fayol, tales como Peter. Drucker, Ernerst Dale, Harold Koontz, Willian Newman, Cyrill O’Donnell, Luther Gulick, Lyndall F. Urwick, entre otros.

Dicha re-estructuración tiene su mayor énfasis en el papel del administrador en las organizaciones, especialmente en las funciones que a este le corresponden, donde los principios generales de administración son los que conducen al administrador en el correcto desempeño de sus tareas (Chiavenato, 2006) (Hurtado , 2008)

Por lo tanto, el proceso administrativo es fundamental para la labor en la organización ya que consiste en "identificar las funciones de los administradores y, enseguida, deducir de ellas los principios fundamentales de la complicada práctica" (Chiavenato, 2006, pág. 127) 1 (Robbins \& Decenzo, 2002). Dichas funciones están dadas por la planeación, la organización, la dirección y el control; aunque estas pueden variar de acuerdo al enfoque de cada teórico neoclásico.

El desarrollo de tales funciones como un todo, es llamado el proceso administrativo (Chiavenato, 2001) o el ciclo del administrador, cuyo objetivo principal es alcanzar la eficiencia ${ }^{2}$ y la eficacia $^{3}$ organizacional mediante el cumplimiento de los objetivos propuestos para generar los resultados esperados por la organización.

Dicho proceso se caracteriza por ser un "sistema integral, complejo, interactivo, flexible y dinámico" (Bernal \& Sierra, 2008, pág. 49); donde el desempeño de cada función tiene consecuencias en el desarrollo de la siguiente, permitiendo que el fin de un aspecto determine el inicio del otro, estableciendo una constante retroalimentación de funciones, actividades y procedimientos.

\footnotetext{
${ }^{1}$ Tomado de Chiavenato, 2006, citado de Peter F. Drucker, Management: Tasks, Responsabilities, Practices, Nueva York: Harper \& RowPublishers, 1974

2 La eficiencia organizacional está orientada hacia resolver los posibles problemas que se efectúen en una empresa; se encarga de cumplir con las tareas y las obligaciones, por medio de métodos, medios y procedimientos. Es la capacidad que tiene una empresa para satisfacer las necesidades de la sociedad a través de los productos que ofrezcan. Es decir, hablar de eficacia, es referirse a la mejor optimización de los recursos que una organización pueda tener (Chiavenato, 2006).

3 La eficacia organizacional está orientada hacia los objetivos y los resultados. Es la relación entre los insumos y los productos, entre los costos y los beneficios, entre los recursos utilizados y el producto final obtenido. Es decir, hablar de eficacia, es referirse a verificar que las actividades se hayan realizado bien hechas, utilizando los recursos suministrados por la organización (Chiavenato, 2006).
}

En este orden de ideas, no existe un tiempo determinado para el completo desarrollo de cada función, por lo tanto, no se puede establecer cuando tiempo es el aproximado para que se efectue de la mejor manera unafunción y otra, esto depende exclusivamente del tiempo destinado al cumplimiento de los objetivos de la empresa.

Dicho proceso, tambien se caracteriza por ser un sistema abierto, en la medida de que se encuentra sujeto a todos los cambios tantos internos como externos en la organización. En este sentido, una sola función puede ser afectada, cambiada o condicionada con un solo cambio que tenga la empresa en su desarrollo, por ejemplo si existe una reducción del personal, si hay una demanda de algun cliente, 0 si existen falencias en las maquinarias. Es decir, el proceso administrativo, esta sujeto a gran cantidad de variables desarrolladas al interior de la empresa, que pueden afectar todo lo establecido para cada función administrativa. (George \& Lourdes, 2005)

Por otro lado, el proceso administrativo tambien se encuentra sujetoa los cambios externos de la organización, principalmente por el contexto en el cual se desarrolle la misma, dados por cambios tecnologicos, generados por la rapida globalización.Otros cambios pueden estar dados, por la competencia del mercado, la competitiva de los productos ofertados, o el desarrollo y la aceptabilidad que tenga el producto en el sector económico en el cual se desarrolle.

Por lo anterior, el proceso administrativo es una herramienta indispensable para todo tipo de organizaciones, ya que puede ser desarrollado con diversos enfoques. Un ejemplo de ello es el enfoque de la teoria general de sistemas y contingencias, donde se relaciona dicha teoria con cada función; por ejemplo, el control, ya que como manifiestan algunos autores, "Cuando la tarea es de rutina, los criterios de evaluación de desempeño son más y exigen eficiencia" (Velasquez, 2000).

En este orden de ideas, para definir y presentar las funciones administrativas del proceso administrativo se tomará a cinco referentes teoricos, a saber: Harold Koontz (1994), Cyril O’Donnell (1975), Heinz Weihrich (2008), William Newman (1951)y Michael Porter (1980) para el desarrollo de este trabajo. Siendo los cuatro primeros autores con aportes de la teoría neoclásica de la administración y el ultimo una autoridad en materia de competitividad, estrategias e innovación en las organizaciones. 


\section{Gráfica 1. \\ El Proceso Administrativo}

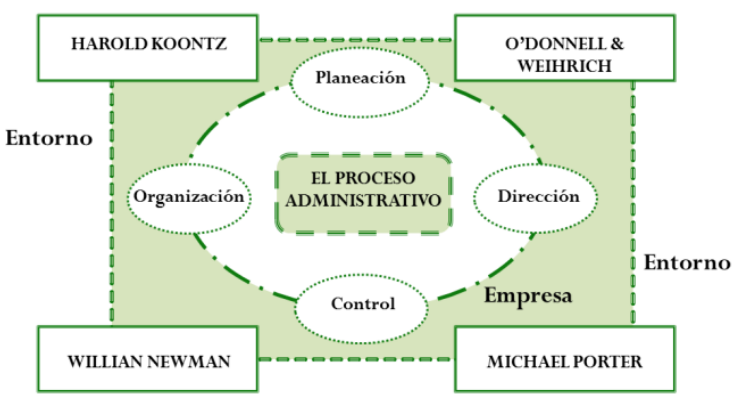

Fuente: (Chiavenato, 2006, pág. 143) - Elaboración propia

En la gráfica 1, se presenta la interacción dinámica que poseen las funciones del proceso administrativo, donde se evidencia que es un ciclo dinámico, abierto y flexible, como se mencionó anteriormente, sujeto a cambios internos y del entorno. Además de esto, se presenta la relación de las respectivas funciones frente a los aportes de los teóricos mencionados que hacen parte de este trabajo.

\section{La planeación: El inicio de un proceso, una ruta de acción.}

La primera función del proceso, para muchos autores es tal vez la más importante ya que define aspectos importantes para las organizaciones como son: el establecimiento de objetivos, metas, estrategias y planes de acción que se deben alcanzar en un determinado tiempo. De igual forma, la planeación va impactar la toma de decisiones, e involucra una gran cantidad de variables que se deben potencializar en las empresas.

Según Koontz, O’Donnell y Weihrich 4 , la planeación implica seleccionar misiones y objetivos, y requerirá tomar decisiones en el futuro para poder elegir los cursos de acción que la empresa deberá seguir, estableciendo que la planeación y el control están fuertemente ligados, ya que como ellos afirman"todo intento de control sin planes carece de sentido" (Koontz \& Weihrich, 2004, pág. 123).

Estos tres referentes teóricos, postulan gran cantidad de variables que toda organización debe desarrollar en su práctica administrativa, entre ellas los planes, los cuales los clasifican en propósitos 0 misiones, objetivos o metas, estrategias, políticas, procedimientos, reglas, programas y presupuestos. De igual forma postulan el uso de la visión y la misión, la toma de decisiones y la innovación

4Koontz, O'Donnell\&Weihrich establecen que son cinco las funciones del administrador, las cuales están dadas por la planeación, la organización, la integración del personal, la dirección y en control. administrativa, como fundamentales en el proceso de planeación de una organización. (Koontz \& Weihrich, 2004)

En primer lugar, ellos consideran que toda empresa u organización tiene un propósito o una misión determinada de acuerdo a la actividad que realice; ya que como ellos afirman: "En todo sistema social, las empresas tienen una función o tarea básica que la sociedad les asigna" (Koontz \& Weihrich, 2004, pág. 124). Por ejemplo, el propósito en una empresa comercializadora, es producir y distribuir los productos o servicios que ellos ofrezcan.

En segundo lugar, establecen que los objetivos y las metas son fundamentales, porque son los fines últimos de la organización a los cuales se quiere llegar, siendo la finalización de todas las actividades establecidas. En tercer lugar, estos tres referentes nos definen como programa el uso de un curso de acción a seguir en un determinando tiempo; ya que como manifiestan: "los programas son complejos de metas, políticas, procedimientos, reglas, asignaciones de tareas, pasos que han de seguirse, recursos que han de emplearse y otros elementos necesarios para llevar a cabo un curso de acción" (Koontz \& O'Donnell, 1976, pág. 153).

En la misma línea, dichos autores evidencian la importancia de un presupuesto como elemento tanto de planeación y de control, ya que al establecer un presupuesto se crea automáticamente el plan de utilidades del cual la organización dispondrá para futuros eventos 0 actividades. Los presupuestos se pueden adoptar tanto para los términos financieros, como para las unidades producidas, en función de horas-actividades 0 en función de horas-máquina (Koontz \& O'Donnell, 1976).

Así mismo, consideran que la toma de decisiones en el proceso de la planeación es esencial, ya que no puede existir un plan sino se ha tomado una decisión con anterioridad; "la toma de decisiones es la selección de un curso de acción entre varias alternativas, y constituye por lo tanto la esencia de la planeación" (Koontz \& Weihrich, 2004, pág. 190); se necesita ser razonable para tomar una correcta decisión, teniendo claras todas las opciones y pensando en las consecuencias de las mismas.

Por otro lado, para Willian Newman5la planificación consiste en establecer los pasos a seguir o las rutas de acción, es decir, es planificar el futuro teniendo una decisión previa de lo que debe hacer en la organización, ya

5William Newman establece que las funciones del administrador están dadas por lo que él llama el "Ciclo de las tareas directivas", compuesto por cinco funciones, las cuales son planificar, organizar, coordinar los recursos, dirigir y controlar, las cuales sirven de guía, estructura y conducción para alcanzar los objetivos de un determinado grupo de individuos. Sin embargo, el propone una sexta función dada por el cumplimiento de las actividades del directivo que no han sido delegadas con anterioridad. 
que como él manifiesta, "planificar es decidir por anticipado que es lo que hay que hacer" (Newman W. , 1974, pág. 33); teniendo unos objetivos claros, un establecimiento de políticas claras, una correcta fijación de los programas y campañas, una buena determinación de métodos y procedimientos específicos y la correcta previsión del "quehacer" en el día a día de las organizaciones (Newman W. , 1974).

Para Newman la iniciativa individual de todas las personas involucradas al interno de la organización es importante, porque permite consolidar una empresa abierta a los comentarios, sugerencias y críticas de los empleados, como también ser innovadores, creativos y retadores con los planes que se proponen; ya que considera que el uso de una planificación extensa para los diversos operarios y supervisores, tiende a ahogar sus iniciativas, creando hombres y mujeres autómatas (Newman W. , 1974).

De igual forma, él propone los métodos estándar en la planeación, ya que afirma que de hacerlo, los resultados se reflejaran en un mejoramiento en la eficiencia organizacional, favoreciendo la calidad del trabajo y los productos ofrecidos. Otros aspectos importantes para este referente en el proceso de la planeación, están dados por la toma de decisión, la logística en las estrategias y los proyectos.

Por otro lado, para Michael Porter6la esencia de la planeación está basada en generar estrategias para alcanzar las ventajas competitivas de la organización frente a otras del mismo sector, donde se crean las acciones que se aplicarán a las diferentes áreas funcionales de la empresa, ya que como el manifiesta "una estrategia de unidad de negocios es el medio de conseguir la ventaja competitiva que regirá su desempeño". (Porter, 2009, pág. 25).

Las variables que el propone están dadas por las estrategias genéricas, las ventajas competitivas, la competitividad, la tecnología y la innovación empresarial, las cuales toda organización debe tener para llegar a ser eficaces y eficientes organizacionalmente.

En primer lugar, la innovación para Porter es esencial, ya que por medio de esta se crean las ventajas competitivas de las organizaciones, a fin de obtener y generar los mejores resultados, ya que como él afirma:

Las empresas crean ventaja competitiva al percibir 0 descubrir nuevas y mejores

\footnotetext{
${ }^{6}$ Michael Porter en un experto académico en la dirección de las empresas y la competitividad organizacional; por lo tanto, este referente no aborda el proceso administrativo como un elemento esencial en la organizaciones desde las cuatro funciones del administrador. En este sentido, para la elaboración de este trabajo, sus aportes se ubicaran dentro del proceso de la planeación, siendo esta función la que más se ajusta a sus trabajos.
}

formas de competir en un sector y trasladarlas al mercado, lo que en último extremo es un acto de innovación. La innovación se define aquí en sentido general, a fin de incluir en ella tanto las mejoras en la tecnología como los mejores métodos o formas de hacer las cosas (Porter, 1991, pág. 78)

Pero la innovación no debe estar guiada exclusivamente hacia la formulación de los planes o las estrategias, también debe estar condicionada para el mejoramiento de los productos y servicios que ofrezca la organización. Se debe ser creativo, innovador y retador para llegar a ser competitivos en el sector económico. En este sentido, Porter manifiesta:

Las empresas deben estar en condiciones de innovar en la vanguardia mundial. Deben crear y comercializar una serie de nuevos productos y procesos que desplacen la vanguardia de la tecnología, avanzando con la misma rapidez con la que sus rivales se ponen a su altura (Porter, 2006, pág. 7).

En segundo lugar, una empresa competitiva debe conocer a sus competidores, para a partir de allí, poder superarlos, y se hace evidente en: "La empresa debe analizar la estructura de su sector y los competidores, conocer sus compradores y las fuentes de valor para ellos, diagnosticar su posición relativa de costos, e intentar establecer una ventaja competitiva sostenible dentro de algún panorama competitivo" (Porter, 2006, pág. 36).De esta manera, el ser competitivos, ayuda a la organización a mantenerse en el sector en el cual se desarrolle, mediante sus estrategias, su innovación y sus productos.

Por último, otro aspecto importante para Porter es la tecnología, ya que toda empresa que no se actualice con las tendencias que el mercado ofrece, se verá estancada en cierta forma en el pasado, y alcanzada en un corto plazo por la competencia, ya que como el afirma: "Cualquiera de las tecnologías que lleva consigo una empresa puede tener una importante repercusión sobre la competencia. Una tecnología es importante a efectos de la competencia si incide notablemente sobre la ventaja competitiva de la empresa o el sector" (Porter, 2006, pág. 117)

Por lo tanto, se puede determinar que la planeación es el camino a seguir, es el establecer el paso a paso en el día a día de las organizaciones. En sí, es trazar una ruta de acción para poder establecer mecanismos que permitan alcanzar una meta; dentro de las organizaciones se visualiza con la configuración de la misión y visión, las cuales inician en una etapa emprendedora y concluyen en 
un ciclo formal, ya que como establece Castaño: "La planeación estratégica adopta patrones de comportamiento de acuerdo con el ciclo de desarrollo de la empresa: va de un ciclo de emprendedor -informal- a uno de planeación formal-, lo que afecta directamente la identidad de la empresa" (Castaño, 2010, pág. 150).

De esta manera, se establecen tres variables importantes en el desarrollo de la planeación, a saber: la innovación, la creatividad y la tecnología. Las cuales son herramientas que permitirán la creación de ventajas competitivas y harán una organización más competitiva organizacionalmente. Por ello, el implementar tecnología actualizada con los recientes avances informáticos, será esencial en esta primera función del proceso administrativo; en este sentido: "la planeación hace parte de la función administrativa y a su vez sugiere integrar las áreas tecnológicas e informáticas, aspecto clave para enfrentar el medio complejo y cambiante que se da alrededor de las pymes." (Solano, Riascos, \& Aguilera, 2013, pág. 28).

\section{Organización: La esquematización del lugar al contexto.}

La organización dentro del proceso administrativo, tiene como propósito principal establecer una estructura general y específica frente a las funciones de los individuos de una empresa, estableciendo cargos, puestos y deberes. Esta función se determina por aspectos como la división organizacional, la departamentalización, el uso de un organigrama, la determinación de una línea de mando, la accesoria externa, la implementación de manuales de reglas y reglamentos, entre otros, tal y como se observa en el Cuadro 1.

Para Koontz, O'Donnell y Weihrich organizar es "un proceso mediante el cual el administrador transforma un caos en orden, evita conflictos entre las personas sobre asuntos de trabajo o de responsabilidad y establece un ambiente adecuado para el trabajo de equipo". (Koontz \& O'Donnell, 1976, pág. 308).

Para estos referentes, toda organización debe tener una organización formal, ya que es la estructura de funciones organizada formalmente, donde se evidencia aspectos como una línea de mando, los niveles jerárquicos y la división organizacional divida en departamentos. Entendiendo que "departamento es un área, división o sucursal en particular, de una organización, sobre la cual un administrador posee autoridad respecto del desempeño de actividades especificas" (Koontz \& Weihrich, 2004, pág. 244)

Otras variables importantes que brindan estos referentes están dadas por el poder y la autoridad, entendiendo como poder, la capacidad de un individuo para influir o inducir en las opiniones o acciones de otro individuo; y como autoridad, el derecho propio de un puesto a ejercer sobre una situación, persona u organización (Koontz \& Weihrich, 2004)

En esta misma línea, ellos manifiestan el uso del staff o la accesoria externa que toda organización en algún momento de su trayectoria se verá obligada a recurrir, entendiendo como staff, la ayuda externa o la relación consultiva de la organización con otras entidades; "se refiere a aquellos elementos de la organización que ayudan a la línea a trabajar con más eficiencia para el logro de los objetivos primarios de la empresa" (Koontz \& O'Donnell, 1976, pág. 364).

Según Newman, la organización es la determinación de las tareas de los individuos que se ve reflejada en la departamentalización de la empresa, la cual es esencial tanto para las empresas grandes como para las pequeñas, ya que como él establece "es un proceso de agrupamiento de actividades en secciones con fines directivos". (Newman W. , 1974, pág. 193).

Este referente propone como variables fundamentales la departamentalización de la organización, la delegación de cargos, tareas, puestos y deberes, el papel del staff, la descentralización de la autoridad, el empleo de los comités y la estructura de la organización en cuanto al empleo de un organigrama y unos manuales de reglas.

Para Newman los comités son fundamentales, porque son pequeños grupos de personas que permiten brindan más organización a la empresa, en el sentido de intercambiar ideas, proyectos, planes y estrategias (Newman W. , 1974). Son multifuncionales, en el sentido de que puede existir un comité diferente para determinada función de la empresa, y así se evitar futuros inconvenientes por la asignación de las tareas.

En esta misma línea, Newman postula la importancia de herramientas útiles de comunicación, tales como un organigrama y un manual de reglas, donde: "un organigrama es una exposición grafica de determinados aspectos de la organización, donde se muestran las divisiones principales o puestos principales de las líneas de autoridad" (Newman W. , 1974, pág. 393). Los manuales de reglas se construyen a partir del organigrama y del cargo del individuo, cuya finalidad es existir para ser cumplidos a cabalidad según la normatividad de la organización.

Por último, la organización para Porter, es un área de análisis de fuerzas y debilidades, con el fin de esquematizar aspectos generales enfocados a la competitividad de las organizaciones. (Porter, 1980). 


\section{Dirección: Un ejemplo a seguir, un equilibrio.}

La dirección en el proceso administrativo, está dirigida a las personas que están al frente de las organizaciones. Los administradores, directivos, encargados, etc.; deben ayudar a las personas a cumplir con sus intereses personales y con los de la empresa; logrando una estabilidad entre lo que se quiere, se puede y se hace en las empresas, permitiendo una optimización de los recursos. Por ende, las herramientas de la dirección están enfocadas al uso y optimización del factor humano, la motivación, el liderazgo y la comunicación.

Para Koontz, O'Donnell \& Weihrich, la dirección consiste en influir en las personas, para que estas de acuerdo a su cargo y sus funciones, puedan contribuir al cumplimiento de las metas tanto de la organización como de los pequeños grupos que se consonlidan dentro de estas (Koontz \& Weihrich, 2004); permitiendo que el factor humano sea elemental en esta función, porque se considera al personal no solo como el trabajador, sino como el consumidor, el cual es un individuo de vital importancia en el mercado.

Las variables que proponen estos tres referentes están dados por el factor humano, la motivación, la equidad, las necesidades de los trabajadores, el liderazgo, los grupos, los comités, los equipos y la comunicación. En este sentido, para ellos, el liderazgo es: "influencia, esto es, el arte $o$ el proceso de influir en las personas para que se esfuercen voluntaria y entusiastamente en el cumplimiento de metas grupales" (Koontz \& Weihrich, 2004, pág. 532). Así, el líder será una figura a seguir, para los diferentes trabajadores de la organización, brindando seguridad, experiencia, pasión y conocimiento.

Así mismo, la comunicación es esencial para el buen funcionamiento de las actividades de la empresa, estando presentes en todas y cada una de las funciones del proceso administrativo, ya que permite que exista un buen desempeño de las tareas de cada individuo y hace posible que existan relaciones de compañerismo en la misma organización.

Según Newman, la dirección es un paso esencial en la administración porque como el postula "es la forma en que un ejecutivo emite instrucciones a sus subordinados e indica que es lo que debe hacerse". (Newman W. , 1974, pág. 483), haciendo énfasis en que el personal con los cargos más bajos son los que realmente tienen la carga de ejecución de la empresa.

Para Newman, los aspectos a destacar en esta función son la motivación, los incentivos, la coordinación y la supervisión. En este orden de ideas, este referente teórico postula que la motivación depende únicamente de los directivos, ya que como él afirma: "debe desarrollarse en cada individuo un deseo de ejecutar sus deberes eficientemente. El papel de la motivación es intensificar ese deseo" (Newman W. , 1974, pág. 500).

En la misma línea, la coordinación para Newman es la sincronización y la unificación de las funciones, actividades 0 acciones de un grupo de individuos. En tal sentido, existe coordinación cuando el desempeño de esas actividades es armonioso e íntegro, buscando llegar hacia los objetivos de la organización (Newman W. , 1974).

\section{Control: Retroalimentación de los procesos y las funciones.}

La función administrativa de control, es trasversal al proceso administrativo. Esta se encarga de vigilar y supervisar que los anteriores elementos del proceso administrativo hayan sido realizados con éxito; ajustando, evitando y corrigiendo a tiempo las desviaciones que se presenten frente a los planes establecidos. Es fundamental, ya que no sólo conecta todos los aspectos y funciones del administrador con el hacer de la empresa, sino que le da solidez al proceso para cumplir con lo propuesto, alcanzando fundamentalmente los objetivos.

Para Koontz, O'Donnell \& Weihrich, el control es entendido como "la medición y corrección del desempeño a fin de garantizar que se han cumplido los objetivos de la empresa y los planes ideados para alcanzarlos" (Koontz \& Weihrich, 2004, pág. 640). Para ellos, las variables a destacar en esta función son el establecimiento y la medición de normas de desempeño, el establecimiento de puntos críticos para controlar y el presupuesto como técnica del control.

En esta línea, los puntos críticos y las normas son esenciales por que permiten determinar los puntos especiales que se vigilaran con atención, para así, medir el desempeño esperado que se quiere obtener y el desempeño real de la organización frente a determinada actividad (Koontz, O'donnell, \& Weihrich, 1985). Otro gran aspecto a resaltar, es el presupuesto como técnica de control, ya que por medio de este se planea en términos monetarios cuanto serán los resultados esperados.

Según Newman, el control es vigilar si las funciones del proceso administrativo fueron cumplidas y desarrolladas con éxito, es decir, es la seguridad total de la finalización del proceso administrativo, ya que como manifiesta "es asegurarse de que la ejecución concuerde con el plan". (Newman W. , 1974, pág. 539).

Este referente postula que existen tres pasos esenciales en todo proceso de control, a saber: el establecimiento de estándares en puntos estratégicos, la comprobación en 
información sobre la ejecución y la toma la acción correctiva (Newman W. , 1974).

En este sentido, el establecimiento de los estándares en puntos estratégicos estarán dados por la función de planeación; y la acción correctiva, dependerá de la comparación entre los objetivos propuestos y los resultados finales, donde si el resultado es negativo, se tendrá que recurrir a ajustar o modificar los planes, objetivos y metas, haciendo una revisión de cada una de las funciones del proceso administrativo (Newman W. , 1974).

De esta manera, es importante destacar que una vez finalizado el proceso administrativo, por la etapa del control, se dan los procesos de realimentación de funciones, lo que permite que este ciclo pueda volver a empezar, ya que al ser dinámico y flexible facilita que las empresas se ajusten a las necesidades y al contexto del mercado.

Sin embargo, es vital aclarar que no existe un lapso establecido de tiempo entre el cumplimiento de cada función, ya que esto depende de cómo la empresa o el ente organizacional lleve a cabo sus objetivos y planes, es decir, el tiempo puede ser relativamente corto, como puede perdurar años; en este sentido: "Evidentemente, primero es el programa(o la meta) y despues el control (o la verificación), aun cuando, insisto, pueda pasar un lapso minimo entre ambas" (Galicia, 2000, pág. 9).

\section{Mipymes en Colombia.}

En Colombia existe la ley 905 del 2004, ${ }^{7}$ la cual determina el desarrollo de las micro, pequeñas y medianas empresas, específicamente en el capítulo 1: "Disposiciones generales", donde establece: "se entiende por micro incluidas las Famiempresas pequeña y mediana empresa, toda unidad de explotación económica, realizada por persona natural o jurídica, en actividades empresariales, agropecuarias, industriales, comerciales o de servicios, rural o urbana" (Ley 905 de 2004).

En la misma línea, dicha ley también establece que una organización es considerada pyme cuando cumple con dos parámetros fundamentales, a saber: tener una planta de personal, con una cantidad establecida de trabajadores y unos activos totales establecidos por medio del Salario Mínimo Mensual Legal Vigente (SMMLV) ${ }^{8}$ determinado por el gobierno colombiano. (Ver Cuadro 2).

7 Ley 905 del 2004 es la modificación de la Ley 590 del 10 de julio del 2000, la cual hace referencia a la promoción del desarrollo de la micro, pequeña y mediana empresa colombiana y se dictan otras disposiciones; se encuentra disponible en el Código de Comercio de Colombia.

8 En Colombia, el Salario Mínimo Mensual Legal Vigente para el presente año 2014, está destinado a $\$ 616.027$ pesos colombianos,
Cuadro 2.

Clasificación de las Mipymes en Colombia.

\begin{tabular}{|c|c|c|}
\hline TIPOS DE EMPRESAS & PLANTA DE PERSONAL & ACTIVOSTOTALES \\
\hline MICROEMPRESA & No superior a 10 trabajadores. & $\begin{array}{c}\text { Inferior a 501 SMMLV } \\
\text { Inferior a 152.780 USD. }\end{array}$ \\
\hline PEQUENA EMPRESA & Entre 11 y 50 trabajadores. & $\begin{array}{c}\text { Entre 501 y 5001 SMMLV } \\
\text { Entre } 152.780 \text { USD. y } 1.525 .060,00 \text { USD }\end{array}$ \\
\hline MEDIANA EMPRESA & Entre 51 y 200 trabajadores & Entre 5001 y 15000 SMMLV \\
& & Entre 1.525 .060 USD y 4.574.257USD \\
\hline
\end{tabular}

Fuente: Ley 905 de 2004. Elaboración propia

\section{Empresas de Servicios Publicitarios.}

Serán entendidas como empresas de servicios todas aquellas que ofrezcan un producto intangible al mercado, permitiendo satisfacer las necesidades de los consumidores; las principales actividades de este sector están dadas por la prestación de servicios tales como la asesoría, la capacitación, la recreación, y la publicidad, entre otros; el sector en el cual se desarrollan las empresas analizadas es el sector de servicios publicitarios.

Actualmente, y con el rápido crecimiento desacelerado de la sociedad, la publicidad se vuelve un tema fundamental para todos los diversos sectores, ya que esta influye de manera importante en todos los consumidores del mercado, siendo esta entendida como"todas aquellas actividades por medio de las cuales mensajes visuales, audiovisuales u orales son enviados a cierto público, con el propósito de informarle e influirle a comprar productos 0 servicios, 0 a actuar o inclinarse favorablemente hacia ideas, personas o instituciones" (Acosta, 1980, pág. 5)

De esta manera, tener una óptima publicidad de los productos y servicios puede llegar a generar un alto nivel de consumo, permitiendo que la producción de estos productos o servicios sea masiva, generando alta demanda en el mercado; lo que permite entender a la publicidad como un elemento vital en las organizaciones, en especial cuando es creativa e innovadora, ya que como Porter afirma "La ventaja competitiva se deriva fundamentalmente de la mejora, la innovación y el cambio". (Porter, 1991, pág. 717)

Pero hablar del sector publicitario, es abarcar todos los campos posibles de comunicación, como por ejemplo, la internet, la televisión, la radio, la prensa, entre otros. Sin embargo, las empresas aquí presentadas se encargan

aproximadamente 304 dólares americanos, con una tasa de cambio de $\$ 2.020$ pesos colombianos. 
exclusivamente de la creación de la imagen corporativa de las empresas, como elemento fundamental de estas para el reconocimiento en la comunidad por medio de sus avisos publicitarios.

Es decir, las empresas analizadas se encargan de realizar publicidad por medio de avisos exteriores, permitiendo crear imágenes corporativas para las diversas compañías interesadas en adquirir este servicio, las cuales se ven reflejadas en el sello, la marca y el logo de estas organizaciones; en este sector la tecnología y su actualización constante de diseños son herramientas fundamentales que facilitan la productividad en un menor tiempo.

\section{METODOLOGÍA:}

La metodología utilizada en esta investigación es de tipo exploratorio y cualitativo; basada en el estudio de caso de tres Mipymes colombianas del sector de servicios publicitarios $^{9}$; donde la técnica metodológica utilizada fueron una serie de entrevistas al personal de estas empresas con cargos como gerente general, socios 0 accionistas $y$, gerente financiero y contable; $y$ observaciones cualitativas frente a la práctica administrativa de las empresas.

\section{Técnica Metodológica.}

El desarrollo de esta investigación tuvo dos técnicas metodológicas, la primera de ellas dada por entrevistas semiestructuradas formuladas de igual manera y siguiendo el mismo orden secuencial de preguntas a las empresas analizadas, y la segunda, por observaciones directas con sistematización cualitativa a las variables de estudio que se establecieron al inicio de la investigación.

Dichas entrevistas fueron realizadas en dos momentos, con una diferencia de cuatro meses aproximadamente entre ellas. Las entrevistas se realizaron bajo una serie de veinte preguntas semiestructuradas, dándole posibilidad a los entrevistados de ubicar una respuesta acorde a su situación; dichas preguntas estuvieron divididas en las cuatro funciones del proceso administrativo, estableciendo cinco preguntas para cada función.

El primer momento de las entrevistas estuvo enfocado a conocer sobre el desarrollo de la planeación y la organización, es decir, a indagar sobre la realización y

9Estas tres Mipymes aprobaron que el nombre de sus empresas, sus características y su trayectoria en el mercado fueran mencionadas en este trabajo. desarrollo de los planes, objetivos, metas y estrategias, así como descripción general de las organizaciones durante el tiempo de funcionamiento, dentro de los cuales se les pregunto por los recursos que poseían inicialmente, la organización de la empresa en cuanto a cargos y puestos, la asesoría de organizaciones externas, entre otros.

El segundo momento, fue aproximadamente cuatro meses después de la primera entrevista; en esta ocasión estuvo encaminada a conocer sobre el desarrollo de la dirección y el control; con preguntas guiadas a reconocer el manejo de los empleados y la supervisión que las empresas manejan, es decir, en cómo estas empresas se relacionan con los empleados por medio de la motivación, la comunicación y el liderazgo. De igual manera, se analizó la integración de los aspectos del control, visto desde la planeación y que fundamentan todo el proceso de retroalimentación de las actividades de las empresas.

Frente a las entrevistas realizadas, todas fueron efectuadas con video de grabación, con la autorización de los entrevistados, para tener un soporte técnico de las afirmaciones aquí presentadas. Dichas respuestas 0 afirmaciones de los entrevistados fueron recopiladas y categorizadas, para así, poder sistematizar la información obtenida.

Por último, las observaciones cualitativas se hicieron en cuatro momentos, con el fin de verificar si la información obtenida por los entrevistados, efectivamente concordaba con la práctica real de las empresas. Así mismo, se observó el desempeño del personal, la elaboración de los productos, la comunicación entre los directivos y los empleados, la funcionalidad de establecer cargos y puestos, la motivación, los incentivos y el liderazgo desarrollado en la empresa, entre algunos otros.

\section{Descripción de las empresas objeto de estudio.}

A continuación se presentan las tres empresas analizadas, las cuales son objeto de estudio de esta investigación. Dichas empresas presentan algunas características en común; la primera de ella dada por que las tres pymes pertenecen al mismo sector económico, ya que como se mencionó anteriormente, pertenecen al sector de servicios publicitarios, creando la imagen corporativa de otras organizaciones.

La segunda característica está dada por que estas tres pymes son empresas familiares, constituidas bajo un mismo grupo familiar, pasando de una generación a otra. Es decir, son empresas que llevan varios años en funcionamiento, con experiencia en el sector, y que han 
generado reconocimiento por la calidad tanto de sus productos como de sus precios.

En tercer lugar, para el desarrollo de esta investigación, se buscó que cada una de las empresas analizadas perteneciera a una categoría según la clasificación y regulación de las Mipymes en Colombia, teniendo así, una microempresa, una pequeña empresa y una mediana empresa.

\section{Publisos\&Company S.A.S}

Es una mediana empresa de tipo familiar, constituida hace treinta y tres (33) años, por cuatro socios; es la empresa que mayor cubrimiento y sostenibilidad ha tenido en el mercado por su tamaño; cuenta con cincuenta y cinco (55) trabajadores distribuidos en diez departamentos(Ver cuadro 3). Cuenta con un solo punto para el diseño, la producción y fabricación de los productos, y con siete salas de ventas y oficinas.

Cuadro 3.

Caracterización de las empresas.

\begin{tabular}{|c|c|c|c|c|c|}
\hline EMPRESA & $\begin{array}{c}\text { TIPO DE } \\
\text { EMPRESA }\end{array}$ & $\begin{array}{c}\text { AÑOS EN EL } \\
\text { MERCADO }\end{array}$ & $\begin{array}{c}\text { CANTIDAD } \\
\text { DE SOCIOS }\end{array}$ & $\begin{array}{c}\text { NÚMERO DE } \\
\text { TRABAJADORES }\end{array}$ & $\begin{array}{c}\text { AREAS/ } \\
\text { DEPARTAMENTOS }\end{array}$ \\
\hline $\begin{array}{c}\text { PANALCRYL } \\
\text { SEÑALIZACIÓN S.A.S }\end{array}$ & MICRO & 24 & 1 & 10 & 9 \\
\hline RELIEVES JEZZ LTDA. & PEQUEÑA & 50 & 3 & 17 & 6 \\
\hline $\begin{array}{c}\text { PUBLISOSY } \\
\text { COMPANY S.A.S }\end{array}$ & MEDIANA & 33 & 4 & 55 & 10 \\
\hline
\end{tabular}

Fuente: Sistematización de los datos recolectados.-Elaboración propia

En este orden de ideas, se presenta una breve descripción de cada Mipyme, con sus características principales, con base en los aportes de los referentes teóricos y en la regulación en Colombia para su categorización dependiendo de su planta de personal y de la cantidad de sus activos. Dicha categorización y descripción se puede observar en el cuadro 3.

\section{PanalcrylSeñalización S.A.S}

Es una microempresa de tipo familiar, que lleva aproximadamente veinticuatro (24) años en el mercado; está constituida por un solo socio, el cual es gerente y administrador a la vez. Posee un personal de diez trabajadores y tiene en funcionamiento nueve departamentos en la organización de la empresa, (Ver cuadro 3). Por lo tanto, hay trabajadores que desempeñan varias funciones, en más de un área de la empresa.

\section{Relieves Jezz Ltda.}

Es una pequeña empresa de tipo familiar, constituida por tres socios inicialmente, ya que actualmente cuenta con cinco socios, dado que con el tiempo se integraron los hijos de los propietarios a la junta de socios. Tiene cincuenta (50) años de trayectoria empresarial, siendo pionera en el sector de servicios publicitarios; cuenta con una planta de personal de diecisiete (17) trabajadores, distribuidos en seis departamentos. (Ver cuadro 3).
Variables de estudio en la práctica administrativa a las pymes.

A continuación se presenta el cuadro 1, el cual es una síntesis de las perspectivas teóricas de cada uno de los referentes de este trabajo (Koontz, O'Donnell, Weihrich, Porter y Newman); en este se definen los conceptos claves y las variables que toda empresa (desde su punto de vista) debe integrar en cada una de las funciones del proceso administrativo.

Esta síntesis, es la base del estudio realizado, ya que muestra la manera en cómo se contrastan los aspectos que definen los autores descritos con lo que se refleja, vive y se ve diariamente en las organizaciones, ya que para cada variable hubo un proceso de análisis en la práctica administrativa de cada empresa. Por ello, el cuadro 1, es una manera de puntualizar las ideas de los neoclásicos presentados en este trabajo. 


\section{Cuadro 1:}

Proceso Administrativo

\begin{tabular}{|c|c|c|c|c|}
\hline $\begin{array}{l}\text { VARIABLES } \\
\text { AUTORES }\end{array}$ & PLANEACIÓN & ORGANIZACIÓN & DIRECCIÓN & CONTROL \\
\hline $\begin{array}{c}\text { Harold } \\
\text { Koontz } \\
\text { Cyrill } \\
\text { O'Donnell } \\
\text { Heinz } \\
\text { Weihrich }\end{array}$ & $\begin{array}{c}\text { Planes/Propósitos } \\
\text { Visión / Misión } \\
\text { Objetivos/Políticas } \\
\text { Cronogramas/Presupuestos } \\
\text { Toma de decisiones } \\
\text { Creatividad/Innovación } \\
\text { Metas/Estrategias } \\
\text { Reglas/Programas } \\
\text { Implementación de la Matriz } \\
\text { Dofa }\end{array}$ & $\begin{array}{c}\text { Funciones/Obligaciones } \\
\text { Líneas de autoridad } \\
\text { Niveles Jerárquicos } \\
\text { Unidad de Mando } \\
\text { División Organizacional } \\
\text { Departamentalización } \\
\text { Organización Formal } \\
\text { Organización Informal }\end{array}$ & $\begin{array}{c}\text { Supervisión } \\
\text { Factor humano } \\
\text { Motivación } \\
\text { Liderazgo } \\
\text { Comités } \\
\text { Comunicación } \\
\text { Necesidades del } \\
\text { trabajador }\end{array}$ & $\begin{array}{c}\text { Normas } \\
\text { Puntos críticos } \\
\text { Desempeño } \\
\text { Planes } \\
\text { Cumplimiento } \\
\text { Retroalimentación } \\
\text { Presupuestos } \\
\text { Productividad } \\
\text { Comparación }\end{array}$ \\
\hline $\begin{array}{l}\text { Michael } \\
\text { Porter }\end{array}$ & \multicolumn{4}{|c|}{$\begin{array}{l}\text { Estrategias/Planes/Acciones/Proyecciones/Recursos/Participación/Ventajas/Competencia } \\
\text { Estrategia Competitiva/Competitividad empresarial/Innovación empresarial/Creatividad/Tecnología }\end{array}$} \\
\hline $\begin{array}{l}\text { Willian } \\
\text { Newman }\end{array}$ & $\begin{array}{c}\text { Decisiones/Objetivos } \\
\text { Políticas/Logísticas } \\
\text { Estrategias/Programas } \\
\text { Toma de decisión } \\
\text { Métodos/Procedimientos } \\
\text { Previsiones }\end{array}$ & $\begin{array}{c}\text { Departamentalización } \\
\text { Delegación/Estructura } \\
\text { Límites de autoridad } \\
\text { Staff/Descentralización } \\
\text { Comités/Responsabilidad } \\
\text { Límites de Control }\end{array}$ & $\begin{array}{l}\text { Motivación } \\
\text { Conducta } \\
\text { Incentivos } \\
\text { Coordinación } \\
\text { Supervisión } \\
\text { Instrucción }\end{array}$ & $\begin{array}{c}\text { Resultados } \\
\text { Standars de Control } \\
\text { Medición } \\
\text { Comprobación } \\
\text { Ejecución } \\
\text { Acción Correctiva }\end{array}$ \\
\hline
\end{tabular}

Fuente: Marco teórico.- Elaboración propia

\section{RESULTADOS Y DISCUSIÓN:}

Observación del desarrollo y la aplicación de las variables a estudiar en el proceso administrativo de las tres Mipymes colombianas del sector de servicios publicitario.

En el análisis cualitativo de las entrevistas, se pudo conocer el manejo del proceso administrativo de las empresas anteriormente descritas, para confrontarlas con las variables dadas por los autores neoclásicos (manifestadas en el marco teórico - Cuadro 1) e identificar tanto los puntos positivos como las falencias frente al desarrollo de las funciones administrativas. En este orden de ideas, se presenta un análisis para cada empresa descrita, según su práctica administrativa.

\section{PANALCRYL SEÑALIZACION S.A.S.}

En el desarrollo de la planeación, se encontró que esta Mipyme desde sus inicios estableció una planeación táctica a muy corto tiempo, ya que no pensaron que la empresa fuera un proyecto de tanto tiempo, ni pudiera lograr los logros y reconocimiento que tiene actualmente en el sector de servicios publicitarios. Por ello, establecieron planes menores a cinco años, con base en lo que querían y como lo querían hacer, mediante el uso de programas y cronogramas, con tiempos y funciones establecidas (Ver cuadro 4).
En este sentido, el gerente general de esta empresa afirma: "Cuento con unas metas y objetivos estructurados a partir de las necesidades que presenta la empresa". (Cardona, H. comunicación personal, 23 de febrero de 2014).

Sin embargo con el transcurrir del tiempo se vieron obligados a generar una planeación mayor, es decir, desarrollaron una visión y una misión, acordes a los objetivos de la empresa, las cuales se caracterizaron por ser retadoras, desafiantes y ambiciosas. De igual forma, desarrollaron un presupuesto, para las actividades a realizar, con el fin de evitar gastos innecesarios, generando un plan innovador y creativo para cumplir con sus objetivos (Ver cuadro 4).

Las falencias presentadas en esta primera función, estuvieron dadas por la falta de generar estrategias, por ello, no implementaron la matriz DOFA, desconociendo sus debilidades, oportunidades, fortalezas y amenazas, tanto en el desarrollo interno como en el externo. Lo anterior tuvo repercusiones en su nivel competitivo, ya que se dejaron alcanzar por empresas más pequeñas que tenían menor trayectoria en el sector (Ver cuadro 4).

En su organización, establecieron una departamentalización por función, manejando áreas como contabilidad, ventas, diseño, pintura, entre algunas otras. 
Tuvieron una centralización de la autoridad por parte del gerente, ya que al ser el único socio de la empresa, tenía el poder absoluto de mando; presentaron una organización formal en la estructura de la empresa al asignar puestos de personal para cada departamento (Ver cuadro 4).

En esta función administrativa, las falencias estuvieron dadas por no presentar un organigrama acorde a la realidad de la empresa, ya que no evidencian la accesoria externa a la cual se ven obligados a recurrir constantemente, como por ejemplo accesoria en temas jurídicos y tributarios. De igual forma, tuvieron problemas en la línea de mando de los encargados de algunos departamentos, ya que no había una autoridad definida para las personas que tenían puestos inferiores (Ver cuadro 4).

En la función de dirección, presentaron un gran desarrollo de la comunicación, ya que al ser una microempresa y contar con diez empleados, se facilita comunicación entre el directivo y los subordinados. Dicho directivo, se caracterizó por ser un líder participativo, que los impulsaba a realizar las funciones de los trabajadores de la mejor manera posible, preocupándose por el bienestar y las necesidades de ellos (Ver cuadro 4). Esto lo manifiesta el entrevistado (gerente general):"el factor humano es importante en el crecimiento de la empresa, por eso es importante buscar su bienestar". (Cardona, H. comunicación personal, 10 de abril de 2014).
Las falencias presentadas en el desarrollo de esta función, se evidenciaron cuando al realizar las observaciones cualitativas, se determinó que no existen motivaciones 0 incentivos por parte del directivo hacia los empleados (Ver cuadro 4). De igual forma, no se desarrollan los comités en esta empresa, por el poco personal, lo que trae dificultades en el sentido de generar un orden interno y un desempeño de funciones acorde a las actividades a realizar.

Finalmente, en el análisis del control, se encontró que las técnicas que esta empresa utiliza para efectuar esta función, están dadas por la vigilancia del desempeño de las actividades de los individuos, como también por la preocupación de que los productos sean entregados puntualmente a los diversos clientes.

De igual forma, otro punto favorable en el análisis de esta función, fue la implementación del presupuesto como técnica de control, ya que determinaron el monto económico para los eventos y actividades, evitando gastar en costos innecesarios de producción. En este sentido, tuvieron grandes falencias en el control, dadas por la medición del desempeño organizacional y la falta de asignar puntos críticos, los cuales se vigilarían constantemente en la productividad de la empresa.

Cuadro 4.

Análisis de las variables desarrolladas en la práctica administrativa de Panalcryl Señalización S.A.S (Empresa 1)

\begin{tabular}{|c|c|c|c|c|}
\hline $\begin{array}{l}\text { EMPRESA I:PANALCRYL } \\
\text { SENEALIZACIÓN S.A.S } \\
\text { (Análisis de la Empresa) }\end{array}$ & PLANEACIÓN & DRGANIZACIÓN & DIRECCIÓN & CONTRUL \\
\hline $\begin{array}{c}\text { VARIABLES } \\
\text { APUCADAS EN LA } \\
\text { EMPRESA }\end{array}$ & $\begin{array}{c}\text { Tuvieron en } \\
\text { cuenta los planes, } \\
\text { los objetivos y las } \\
\text { metas. Usaron } \\
\text { cronogramas y } \\
\text { presupuestos. }\end{array}$ & $\begin{array}{l}\text { Tuvieron una } \\
\text { departamentalización } \\
\text { por funciones, } \\
\text { asignando puestos, } \\
\text { tareas y deberes. }\end{array}$ & $\begin{array}{c}\text { Tuvieron un líder } \\
\text { participativo, que se } \\
\text { preocupo por las } \\
\text { necesidades de sus } \\
\text { empleados. }\end{array}$ & $\begin{array}{c}\text { Vigilaron y } \\
\text { supervisaron el } \\
\text { trabajo de los } \\
\text { individuos, e } \\
\text { hicieron uso de un } \\
\text { presupuesto para } \\
\text { controlar. }\end{array}$ \\
\hline $\begin{array}{c}\text { VARIABLES NQ } \\
\text { APUCADAS EN LA } \\
\text { EMPRESA }\end{array}$ & $\begin{array}{c}\text { No generaron } \\
\text { estrategias en su } \\
\text { planeación, por ello } \\
\text { no implementaron la } \\
\text { Matriz Dofa. }\end{array}$ & \begin{tabular}{|} 
Tienen falencias en su \\
organigrama, no \\
evidencia el uso de staff. \\
No hay niveles \\
jerárquicos de mando.
\end{tabular} & $\begin{array}{c}\text { No hay incentivos, } \\
\text { ni motivaciones } \\
\text { para los empleados. } \\
\text { No manejan los } \\
\text { comités. }\end{array}$ & $\begin{array}{l}\text { No manejan puntos } \\
\text { críticos para } \\
\text { controlar y no } \\
\text { tienen una } \\
\text { retroalimentación } \\
\text { de funciones. }\end{array}$ \\
\hline
\end{tabular}

Fuente: Sistematización de los datos recolectados.-Elaboración propia 


\section{- RELIEVES JEZZ LTDA.}

Relieves JezzLtda., es la segunda pyme analizada en esta investigación, la cual se caracterizó por presentar resultados realmente negativos frente a la descripción teórica de los neoclásicos; dichos resultados implicaron que en el desarrollo de este trabajo, esta empresa se viera obligada a liquidar, es decir, tuvo que necesariamente cancelar su actividad de producción por las grandes falencias encontradas en su práctica administrativa. Tales falencias se encontraron en las cuatro funciones del proceso administrativo.

En la función de planeación, presentaron puntos positivos, en cuanto a establecer una visión y una misión acordes a sus objetivos y metas, teniendo en cuenta que querían hacer y adonde querían llegar; por ello, implementaron estrategias de competencia para el sector en el cual se estaban desarrollando, logrando ser reconocidos como una empresa potencial frente a los competidores, lo que les permitió fijar un cronograma en función del logro y el cumplimiento de cada una de las tareas encargadas a los trabajadores (Ver Cuadro 5).

\section{Cuadro 5.}

Análisis de las variables desarrolladas en la práctica administrativa de Relieves Jezz Ltda. (Empresa 2) creativos con los productos ofertados, y al no actualizar su tecnología y maquinaria para su producción.

En este sentido, "La tendencia hacia la globalización implica exigir trabajo competitivo en las organizaciones, 10 que ha conducido a muchas empresas a reducir su tamaño" (Mota, 2014)10 e inclusive a terminar con la empresa, como fue el caso de esta Mipyme. Por ello, las falencias encontradas en esta función estuvieron guiadas a la innovación y a la tecnología, ya que al ser una empresa con una trayectoria empresarial de cincuenta años en el mercado, era recomendable la actualización constante de su práctica administrativa, siendo innovadores, creativos y retadores en sus actividades.

En la organización, presentaron una departamentalización por función establecida en seis áreas, a saber: contabilidad, producción, ventas, diseño, recursos humanos y servicios generales; en este sentido un socio de esta empresa declara:"Tenemos una organización establecida por áreas, donde solo se elaboran tareas realizadas por nuestros operarios". (Osorio, A. comunicación personal, 18 de marzo de 2014).

\begin{tabular}{|c|c|c|c|c|}
\hline $\begin{array}{c}\text { EMPRESA 2: RELIEVES } \\
\text { JEZ7 LTDA. } \\
\text { (Análisis de la Empresa) }\end{array}$ & PLANEACIÍN & QRGANIZACIÍN & DIRECCIÓN & CONTRLL \\
\hline $\begin{array}{c}\text { VARIABLES } \\
\text { APUCADAS EN LA } \\
\text { EMPRESA }\end{array}$ & $\begin{array}{l}\text { Establecieron misión } \\
\text { y visión, planes y } \\
\text { objetivos. Generaron } \\
\text { estrategias a corto } \\
\text { plazo. }\end{array}$ & $\begin{array}{c}\text { Tuvieron una } \\
\text { centralización de la } \\
\text { autoridad. Asignaron } \\
\text { puestos y tareas a sus } \\
\text { trabajadores. }\end{array}$ & $\begin{array}{c}\text { Tuvo un Líder } \\
\text { Autocrático, que } \\
\text { exigía una } \\
\text { supervisión estricta } \\
\text { y una obediencia } \\
\text { total. }\end{array}$ & $\begin{array}{c}\text { Usan los } \\
\text { cronogramas } \\
\text { como técnica de } \\
\text { control y la } \\
\text { comparación de } \\
\text { periodos contables }\end{array}$ \\
\hline $\begin{array}{l}\text { VARIABLES ND } \\
\text { APUCADAS EN LA } \\
\text { EMPRESA }\end{array}$ & $\begin{array}{l}\text { No fueron creativose } \\
\text { innovadores en sus } \\
\text { planes. Tuvieron } \\
\text { serios problemas por } \\
\text { falta de nueva } \\
\text { tecnología. }\end{array}$ & $\begin{array}{l}\text { No desarrollaron un } \\
\text { manual de } \\
\text { reglamentos. No } \\
\text { evidenciaron el staff } \\
\text { que constantemente se } \\
\text { ven obligados a usar. }\end{array}$ & $\begin{array}{c}\text { No hay } \\
\text { comunicación, no } \\
\text { existe un liderazgo } \\
\text { a seguir. No hay } \\
\text { motivación,ni } \\
\text { incentivos. }\end{array}$ & $\begin{array}{l}\text { No manejaron } \\
\text { puntos críticos } \\
\text { para controlar. } \\
\text { No hay } \\
\text { retroalimentación } \\
\text { de funciones. }\end{array}$ \\
\hline
\end{tabular}

Fuente: Sistematización de los datos recolectados.-Elaboración propia

En esta medida, esta pequeña empresa tuvo su éxito organizacional en el inicio de su desarrollo, pero con el pasar de los años y con los avances tecnológicos del contexto, se quedaron estancados en el pasado al no estar contantemente innovando sus planes, siendo poco 
Presentaron una centralización de la autoridad en el desarrollo de esta función, permitiendo tener una organización formal frente a las líneas de mando y los niveles jerárquicos de la empresa; asignaron cargos, puestos, tareas y deberes para el desarrollo de las actividades, permitiendo ser eficientes y eficaces organizacionalmente. De igual forma, las observaciones cualitativas establecieron que en el desempeño interno de esta empresa, se presenta una organización informal por parte de los empleados en pequeños grupos de interés (Ver Cuadro 5).

Las falencias encontradas estuvieron dadas por la falta de implementación de un manual de reglas y reglamentos para los trabajadores de la empresa, lo cual tuvo consecuencias en la disminución de los índices de productividad, con impuntualidad en llegadas tarde de los mismos, faltas ofensivas entre ellos e incumplimiento con las tareas y funciones asignadas (Ver Cuadro 5).

Otro punto negativo estuvo dado por no recurrir a alguna accesoria externa, lo cual tuvo consecuencias en hacer las cosas eficazmente pero no eficientemente, ya que no tenían la mejor optimización de los recursos frente a las actividades o eventos que no manejaban completamente; en este sentido un socio de la empresa afirma: "En nuestra trayectoria no hemos tenido acceso alguno a ayudas externas". (Osorio, A. comunicación personal, 20 de abril de 2014).

En la función de dirección, se encontró un liderazgo autocrático por parte del gerente general, quien a su vez era un socio de la junta directiva. Dicho liderazgo se caracterizó por exigir al máximo la supervisión de las actividades del personal, y por imponer una obediencia total por parte de los mismos, presentando falencias en la carencia de no establecer una comunicación acorde a las necesidades de la empresa y en el no presentar preocupación alguna por el bienestar y las necesidades de los empleados en el desarrollo de sus funciones. Por ello, en las observaciones cualitativas no se encontraron motivación o incentivo alguno por parte de los directivos hacia los empleados para el logro del cumplimiento de sus actividades (Ver Cuadro 5).

\section{Cuadro 5. Análisis de las variables desarrolladas en la práctica administrativa de Relieves Jezz Ltda. (Empresa 2) cerca}

Fuente: Sistematización de los datos recolectados.Elaboración propia

En el desarrollo de la función del control, se encontró que evidentemente generaron una supervisión estricta por el tipo de liderazgo que manejaron, estableciendo el uso de cronogramas y el presupuesto como técnicas de control. En esta función, el gerente manifestó que otra técnica de control para ellos, es la comparación de periodos contables, los cuales les dan señales de estar haciendo las cosas bien hechas (Ver Cuadro 5).

Sin embargo, no manejaron el control de la mejor manera, ya que se presentaron falencias en la falta de determinar reglas, normas y puntos críticos para controlar. Otra variable que no fue aplicada éxito fue que manifestaron que no hay una realimentación de funciones por medio de esta función (Ver Cuadro 5).

\section{- PUBLISOS Y COMPANY S.A.S}

Esta mediana empresa del sector publicitario, presento un excelente desempeño en la mayoría de las funciones del proceso administrativo, con base en las variables establecidas por lo referentes teóricos. En la planeación, establecieron una misión y una visión acordes a las características (ambiciosas y retadoras); se preocuparon por tener valores, principios y una filosofía según las actividades de la organización. Fijaron una planeación estratégica, generando planes, objetivos, metas y estrategias a largo plazo, a través del uso de la matriz DOFA. Dichas estrategias se caracterizaron por ser innovadoras y creativas, lo que les permitió crear ventajas competitivas frente a otras organizaciones del mismo sector (Ver Cuadro 6).

Sin embargo presentaron falencias en la toma de decisiones, ya que al estar constituida por cuatro socios, cada uno presentada diferentes rutas de acción, por lo tanto, cada individuo quería desarrollar diferentes acciones y planes, lo cual tuvo dificultades en establecer el futuro de la empresa (Ver Cuadro 6).

En la función de organización, se encontraron muy buenos resultados, ya que aplicaron cada una de las variables propuestas en este trabajo. En esta función, manejaron un diseño organizacional institucional, abarcando toda la estructura de la empresa, que les permitió establecer una departamentalización por función en diez áreas, tales como: contabilidad, administración, marketing, ventas, diseño, tecnología, entre otras (Ver Cuadro 6).

Así mismo, presentaron una línea de mando basada en los niveles jerárquicos de autoridad de los cargos establecidos en el personal de la empresa, siendo estos reflejados correctamente en el organigrama. Otros puntos a favor, estuvieron dados por presentar una organización informal, establecida por los diversos grupos de interés de los empleados y un correcto cumplimiento del manual de reglas y reglamentos de la empresa (Ver Cuadro 6). 
Las falencias presentadas en esta función estuvieron dadas por la carencia de comités, ya que las funciones eran bien establecidas para cada persona, con el fin de evitar otros grupos subalternos que pudieran tomar decisiones en el funcionamiento de la empresa.

En la cuarta función, establecieron como técnicas de control la vigilancia y supervisión de los cronogramas, los presupuestos y la comparación de periodos contables (Ver Cuadro 6).

Cuadro 6.

Análisis de las variables desarrolladas en la práctica administrativa de Publisos\&Company S.A.S. (Empresa 3)

\begin{tabular}{|c|c|c|c|c|}
\hline $\begin{array}{l}\text { EMPRESA 3:PUBLISOS } \\
\text { Y COMPANY S.A.S } \\
\text { (Análisis de la Empresa) }\end{array}$ & PLANEACIÍN & 口RGANIZACIÍN & DIRECCIÍN & CDNTRLL \\
\hline $\begin{array}{c}\text { VARIABLES } \\
\text { APUEADAS EN LA } \\
\text { EMPRESA }\end{array}$ & $\begin{array}{c}\text { Usaron la matriz Dofa } \\
\text { para generar estrategias. } \\
\text { Fueron creativos e } \\
\text { innovadores en cada } \\
\text { uno de los planes, } \\
\text { objetivos y metas. }\end{array}$ & $\begin{array}{c}\text { Presentación un } \\
\text { organigrama exitoso, } \\
\text { definieron niveles } \\
\text { jerárquicos de mando } \\
\text { Evidenciaron la } \\
\text { accesoria externa. }\end{array}$ & $\begin{array}{l}\text { Tuvieron un líder } \\
\text { participativo, con } \\
\text { alta preocupación, } \\
\text { comunicación, } \\
\text { incentivos y } \\
\text { motivaciones hacia } \\
\text { los trabajadores. }\end{array}$ & $\begin{array}{l}\text { Vigilarony } \\
\text { supervisaron } \\
\text { mediante los } \\
\text { cronogramas, los } \\
\text { presupuestos y la } \\
\text { comparación de } \\
\text { periodos contables. }\end{array}$ \\
\hline $\begin{array}{c}\text { VARIABLES ND } \\
\text { APULADAS EN LA } \\
\text { EMPRESA }\end{array}$ & $\begin{array}{c}\text { Tuvieron } \\
\text { dificultades para tomar } \\
\text { decisiones }\end{array}$ & $\begin{array}{c}\text { No presentan } \\
\text { falencias } \\
\text { organizacionales. }\end{array}$ & $\begin{array}{l}\text { No presentan } \\
\text { Comités. }\end{array}$ & $\begin{array}{l}\text { No conciben el } \\
\text { control como } \\
\text { retroalimentación de } \\
\text { funciones }\end{array}$ \\
\hline
\end{tabular}

Fuente: Sistematización de los datos recolectados.-Elaboración propia

En la tercera función del proceso administrativo, establecieron una alta dirección, implementado un liderazgo participativo, donde el factor humano es esencial para la empresa. Por ello se preocuparon por tener una constante comunicación, facilitando el desempeño y la coordinación de las funciones de todos los individuos de la misma. Desarrollaron altos niveles de motivación e incentivos, de parte de los directivos hacia los empleados, tales como bonificaciones, premios, salidas de integración, entre otras. De esta forma, los entrevistados concordaron que el bienestar del empleado y sus necesidades son importantes, porque por medio de la satisfacción de estas, dicho individuo es más eficaz en el desempeño de sus funciones (Ver Cuadro 6).
De igual forma fijaron normas, reglas y pautas para vigilar, pero no fueron controladas en su totalidad, se determinaron puntos críticos de evaluación, pero estos en ningún momento fueron vigilados, controlados 0 supervisados por los directivos de la empresa.

En este sentido, no concibieron el control como una realimentación de funciones, ya que como lo afirma el entrevistado (gerente financiero): "Se realiza un control a la hora y en el momento de realizar la actividad, mas no se realiza una retroalimentación eficaz a la finalidad de este" (Peña, G. comunicación personal, 5 de abril de 2014). Por lo tanto, consideraron que las funciones del proceso administrativo son aisladas y que no existe una interacción dinámica entre ellas, permitiendo su realimentación. 


\section{Análisis y síntesis de los resultados.}

El proceso administrativo debe ser entendido como una herramienta fundamental y esencial en todo tipo de empresas; principalmente porque el mundo de hoy es inconsistente, con una serie de variaciones constantes, esto debido a los rápidos contextuales en los cuales se desarrollan las empresas, exigiendo que las mismas estén preparadas para afrontar determinadas situaciones. Por ende, estar constantemente planeando, organizando, dirigiendo y controlando permite que las empresas tengan un futuro administrativo exitoso, lo que puede conllevar a un porvenir estable en el mercado en el cual se desarrollen.

Por lo anterior, la administración debe ser entendida como un aspecto esencial en la organización, ya que influye de manera importarte en el desarrollo eficaz y eficiente de las mismas; así pues, como se evidenció en este trabajo, las empresas que actualmente no manejen los aspectos básicos del proceso administrativo se verán perjudicadas y quizás obligadas a cerrar actividades (liquidar la sociedad).

De esta manera las entrevistas realizadas, permitieron conocer el manejo del proceso administrativo de las empresas anteriormente descritas, donde se encontraron grandes dificultades en cuanto al desarrollo de estas funciones en su nivel administrativo, dado por el desinterés en desarrollar una administración exitosa y la exclusiva preocupación por generar rentabilidad económica y financiera a muy corto plazo.

Así mismo, la mala distribución de las funciones del personal, la falta de planes a determinado tiempo, el desinterés de los empleados por ejecutar sus tareas con eficiencia, la falta de un control de planes y objetivos, y más aún importante la falta de innovación constantemente en sus actividades, refleja la inadecuada administración que las Mipymes pueden llegar a tener. En este sentido, la innovación y la creatividad son dos factores que deben desarrollarse en el funcionamiento interno de la organización, permitiendo crear ventajas competitivas frente a otras organizaciones, para lograr el éxito empresarial en el sector en el cual se desarrollen.

Sin embargo, no todos los aspectos en este ciclo administrativo son negativos; es de destacar por ejemplo la función de dirección en una microempresa, donde al contar con poco personal en comparación con una mediana empresas se establece una relación de amistad y compañerismo entre directivos y empleados, permitiendo una comunicación exitosa; independiente del estilo de dirección que posea la empresa. De igual forma, los directivos se preocupan por el bienestar y motivación de los trabajadores, entendiendo que en las pequeñas y medianas organizaciones se puede generar un ambiente familiar.

En este orden de ideas, se presenta el cuadro 7, el cual es síntesis del análisis a las entrevistas realizadas a estas tres Mipymes Colombianas, allí se establecen los resultados de las observaciones de cada función del proceso administrativo, permitiendo hacer una comparación entre ellas, frente a su desarrollo administrativo por medio de valores cuantitativos, específicamente en porcentajes para cada función de este proceso, determinando que el $100 \%$ es la aplicación total de las variables; esto para tener un desarrollo más claro y ordenado de los resultados aquí presentados.

En este sentido, se asignaron dos rangos, donde se podían ubicar los resultados encontrados, el primero de ellos comprendido entre el $0 \%$ y el $59 \%$, estableciendo que en este rango se encuentran los resultados menos favorables, ya que están dados por el gran número de falencias, dificultades y problemas encontrados frente a lo que proponen los neoclásicos del proceso administrativo. Por ello, dicho porcentaje se presenta como un punto negativo para las empresas, siendo representado con una equis $(\mathrm{x})$. El segundo rango está comprendido entre el $60 \%$ y el 100 $\%$, ubicando los resultados más favorables, con la mayor cantidad de variables aplicadas a las empresas mencionadas, dicho porcentaje se presenta como un punto positivo $(\checkmark)$ para estas empresas.

Por medio de estos porcentajes, se realizó un promedio para las empresas, permitiendo hacer una comparación del desarrollo de las funciones, estableciendo tres categorías de los resultados presentados frente a la práctica administrativa, a saber: administración baja, administración media y administración alta. En tal sentido, se presentan los resultados obtenidos.

En primer lugar, la microempresa Panalcryl Señalización S.A.S presento resultados no tan favorables como se esperaba al inicio de esta investigación, ya que aparentaban tener todo en orden; en la planeación presentaron aspectos positivos en un gran número de variables aplicadas y desarrolladas. Sin embargo el no generar estrategias en su planeación, tuvo grandes repercusiones en su desarrollo, por lo tanto, tuvieron un 70 $\%$ en esta función. En la función de organización se presenta un $50 \%$, porque fueron más las falencias encontradas que los puntos positivos, en este sentido, el no tener una línea de autoridad en los respectivos departamentos tuvo consecuencias en el desarrollo de las tareas más pequeñas.

En su dirección, el elemento a destacar es la comunicación, ya que al ser una Mipyme con tan poco personal, la comunicación era rápida, fluida y permitía el 
funcionamiento de las actividades. Sin embargo, el no establecer motivaciones e incentivos, genero la asignación de un $73 \%$ para esta función. En el control, supervisaron y controlaron las actividades por medio de técnicas de vigilancia y control, sin embargo, el no asignar puntos críticos para controlar, manifestando que el control es una etapa más, permitió establecer un 48 \% para esta función. publicidad de 50 años de funcionamiento. Sin embargo, como se presentó en este trabajo, esta pequeña empresa se vio obligada a liquidar, principalmente por dos aspectos, a saber: las grandes falencias en su administración y el sometimiento al pasado al no actualizarse con las herramientas que actualmente ofrece la tecnología y el mundo.

\section{Cuadro 7: \\ Resultados del análisis de las Mipymes en función al proceso Administrativo}

\begin{tabular}{|c|c|c|c|}
\hline $\begin{array}{c}\text { ANÁLISIS DE LAS } \\
\text { MYPIMES EN FUNCIÓN } \\
\text { AL PROCESO } \\
\text { ADMINISTRATIVO }\end{array}$ & $\begin{array}{c}\text { EMPRESA 1: } \\
\text { (MICRO EMPRESA) } \\
\text { PANALCRYL } \\
\text { SEÑALIZACION S.A.S }\end{array}$ & $\begin{array}{c}\text { EMPRESA 2 : } \\
\text { (PEQUEÑA EMPRESA) } \\
\text { RELIEVES } \\
\text { JEZZ LTDA }\end{array}$ & $\begin{array}{c}\text { EMPRESA 3: } \\
\text { (MEDIANA EMPRESA) } \\
\text { PUBLISOS \& } \\
\text { COMPANY } \\
\text { S.A.S }\end{array}$ \\
\hline PLANEACIÓN & $\checkmark \quad(70 \%)$ & $\begin{array}{ll}\checkmark(60 \%) \\
\end{array}$ & $\checkmark \quad(80 \%)$ \\
\hline ORGANIZACIÓN & $\begin{array}{ll}\mathrm{X} \quad(50 \%) \\
\end{array}$ & $\begin{array}{ll} & (50 \%)\end{array}$ & $\begin{array}{ll}\checkmark \quad(100 \%) \\
\end{array}$ \\
\hline DIRECCIÓN & $\begin{array}{ll}\checkmark(73 \%) \\
\end{array}$ & $\begin{array}{ll} & (20 \%)\end{array}$ & $(90 \%)$ \\
\hline CONTROL & X (48\%) & X $(55 \%)$ & $\mathrm{X} \quad(57 \%)$ \\
\hline $\begin{array}{c}\text { CONCLUSIONES } \\
\text { FRENTE AL PAPEL DEL } \\
\text { ADMINISTRADOR }\end{array}$ & $\begin{array}{c}\text { Administración eficaz, } \\
\text { pero no eficiente. } \\
\text { Total: } 6025 \% \\
\text { (Media) }\end{array}$ & $\begin{array}{l}\text { Administración ni eficaz, } \\
\text { ni eficiente. } \\
\text { Total: } 46,25 \\
\text { (Baja) }\end{array}$ & $\begin{array}{l}\text { Administración eficaz, } \\
\text { pero no eficiente. } \\
\text { Total: } 81,75 \% \\
\text { (Alta) }\end{array}$ \\
\hline
\end{tabular}

Fuente: Análisis de las entrevistas.-Realización propia.

Por lo tanto, al tener un porcentaje bajo en dos de las cuatro funciones, se concluye que tuvo una administración media en la comparación con las otras dos empresas, presentando un 60, $25 \%$ (Ver cuadro 7) en la totalidad de su práctica administrativa. Lo anterior, permite establecer que en su desarrollo tuvieron una administración eficaz, porque realizaron algunas cosas bien hechas, pero no fue una administración eficiente, porque no se realizó de la mejor manera posible, al no tener la mejor optimización de los recursos; siendo principalmente la organización y el control los puntos a mejorar.

En segundo lugar, la pequeña empresa Relieves Jezz Ltda.,generó grandes sorpresas en esta investigación; como se mencionó anteriormente esta empresa es una empresa familiar, caracterizada por pasar de una generación a otra, ya que tuvo un traspaso de padres a hijos, consolidando un trayecto en el mercado de la
En este sentido, en la función de planeación, desarrollaron un $60 \%$ de las variables aplicadas, ya que se vieron en la tarea de fijar planes, objetivos y metas; sin embargo, estas no fueron actualizadas, renovadas y cambiadas, presentando falencias en ser innovadores y creativos, ya que rigieron bajo los parámetros iniciales de la empresa, olvidándose de la actualizando constante que debe tener la planeación. Desde este punto, se puede afirmar, que tuvieron cierto estancamiento en el pasado;en la organización presentaron un $50 \%$ ya que tuvieron grandes falencias como el no establecer un manual de reglas y reglamentos para todos los individuos de la empresa y el no evidenciar la accesoria externa a la cual recurren en varias oportunidades.

La dirección fue la función que menor porcentaje presento, al no desarrollar incentivos, motivaciones, preocupación por las necesidades y el bienestar de los trabajadores, no 
manejar comunicación, ni establecer un liderazgo participativo, por ello se presenta un resultado del $20 \%$ para esta función. El control presento un desarrollo de 55 $\%$ ya que supervisaron y controlaron las actividades de los trabajadores, generando técnicas de control, pero no desarrollaron puntos críticos para controlar, dejando de lado que el control es realimentación de funciones.

De este modo, esta Mipyme presento resultados realmente bajos en tres de las cuatro funciones, obteniendo un promedio de 46,25\%(Ver cuadro 7), generando de la misma manera un porcentaje bajo, dados los rangos establecidos. Por lo tanto, se concluye que tuvo una administración baja frente a las otras dos empresas analizadas, y que su administración no fue eficaz, ni eficiente, ya que solo se preocuparon por generar utilidades a corto tiempo, siendo puntuales con la entrega de los productos ofrecidos, olvidándose de los problemas internos que presentaba la empresa.
En la organización presentaron un resultado del $100 \%$ ya que no tuvieron falencias organizacionales; en este sentido, aplicaron cada una de las variables establecidas (Ver cuadro 1).

En su tercera función, tuvieron un liderazgo participativo hacia los empleados mediante el desarrollo de cada una de las variables, presentando falencias al no establecer comités, ya que consideran que no es necesario. Por lo tanto, se establece un $90 \%$ para esta función. Por último, en el control presentaron un bajo desarrollo al no considerar el control como realimentación de funciones, por lo tanto, se establece un 57 \% para esta función.

De esta manera, los resultados obtenidos para esta mediana empresa están dados por un 81,75 \% (Ver cuadro 7 ), siendo los resultados finales más altos en esta investigación, permitiendo concluir que tuvieron un desarrollo alto en su práctica administrativa al hacer la comparación con las otras dos empresas analizadas.

\section{Cuadro 8. \\ Recomendaciones para la práctica administrativa de las empresas analizadas}

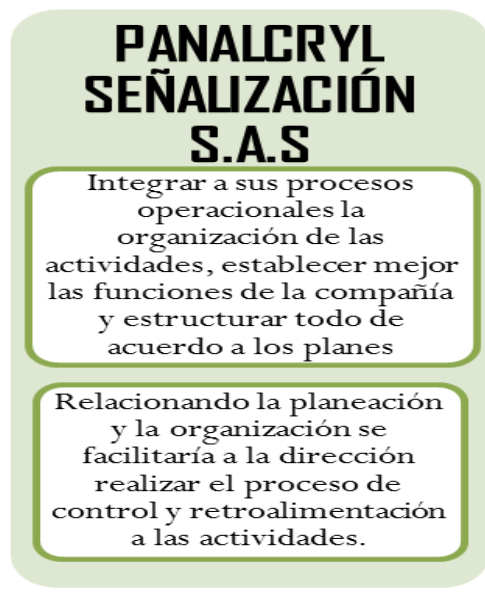

\section{RELEVES JEZZ LTDA}

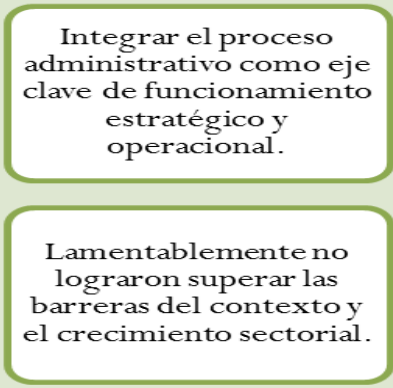

\section{PUBUSOS g CDMPANY S.A.S}

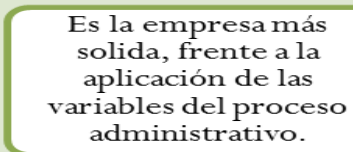
administrativo.

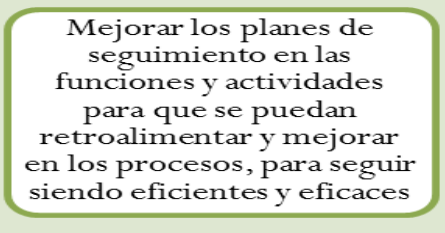

Fuente: Análisis de las entrevistas.-Realización propia.

Finalmente, frente al análisis realizado a Publisos\&Company S.A.S. se encontraron aspectos realmente positivos en su práctica administrativa; en su planeación tuvieron varios puntos positivos al aplicar cada una de las variables establecidas, presentando falencias únicamente en la toma de decisiones, ya que la empresa está dirigida bajo cuatro socios con visiones y perspectivas diferentes, por ello se establece un $80 \%$ en esta función.
Por ello, se establece que tuvieron una administración eficaz pero no eficiente, ya que no generaron la mejor optimización de los recursos al realizar las actividades.

\section{- Recomendaciones para las compañías.}

Frente al análisis realizado y los resultados presentados, esta investigación intenta establecer algunas recomendaciones para la práctica administrativa de estas Mipymes. En el cuadro 8, se presentan algunas 
recomendaciones para cada una de las empresas, ya que se establecen con base en sus resultados.

\section{Cuadro 8. Recomendaciones para la práctica administrativa de las empresas analizadas}

Fuente: Resultados del análisis de las empresas.Realización propia.

En primer lugar, las recomendaciones de Panalcryl Señalización S.A.S están orientadas hacia las funciones de planeación, organización y dirección, ya que son las funciones en las cuales presentaron porcentajes más bajos (Ver cuadro 8). En segundo lugar, las recomendaciones para Relieves Jezz Ltda. (Si desean iniciar actividades nuevamente) están orientadas hacia una re-estructuración y una re-formulación de su proceso administrativo, estableciendo que la administración debe ser esencial si se quiere lograr el éxito empresarial. Finalmente, las recomendaciones para Publisos \& Company S.A.S, están orientadas hacia la planeación y el control, ya que están dos funciones deben ir unidas, en el sentido de que no se puede controlar algo que no ha sido planeado con anticipación (Ver cuadro 7).

\section{CONCLUSIONES:}

Frente a la problemática establecida en esta investigación, acerca de si realmente las empresas colombianas del siglo XXI desarrollan el proceso administrativo tal y como lo plantean los referentes neoclásicos aquí establecidos, no se puede hacer una generalización. La diversidad de empresas en Colombia es grande y variada; por ello, este estudio de caso no puede establecer una respuesta acorde a todos los sectores económicos.

Por lo tanto, este trabajo está enfocado exclusivamente al sector de servicios publicitarios, y allí es donde se presentan las consideraciones finales de esta investigación; en tal sentido, el analizar tan solo tres empresas colombianas, y encontrar resultados negativos en la práctica administrativa de dos de ellas, permite establecer que las empresas colombianas del sector de servicios publicitarios no desarrollan el proceso administrativo tal y como lo plantea la teoría neoclásica; esto debido a cuatro aspectos importantes que serán presentados a continuación.
En primer lugar, existe un sometimiento al pasado, donde las empresas de este sector, no se preocupan por la renovación y el cambio en su estructura administrativa, lo cual genera graves problemas a largo plazo, tal y como se evidencio en este trabajo.

El segundo aspecto está orientado a que estas empresas no consideran que la administración es un factor esencial en toda organización, lo cual genera grandes problemas en todos los diferentes departamentos de la misma.

En tercer lugar, existe una exclusiva preocupación por generar utilidades y ser rentables económicamente a muy corto tiempo, generando interés únicamente en la puntualidad de los productos ofertados; lo anterior implica tanto problemas organizacionales como directivos en el funcionamiento de la empresa.

El cuarto aspecto está dado por el análisis de estas empresas, donde las tres coincidieron en manifestar que el control para ellos es solo una función más, ignorando que por medio de la finalización de esta función el proceso administrativo tiene un nuevo comienzo, permitiendo realimentar las funciones del administrador.

De esta forma, este trabajo permitió conocer que el papel del administrador es esencial y fundamental para toda organización, ya que sus tareas y funciones son las desarrolladas en el proceso administrativo. En este sentido, de no contar con una persona que guie, oriente y administre una organización, esta no funcionaría plenamente. También es importante que el administrador día a día reconozca las variables tanto internas como externas que afectan a su organización y de una manera contingente prevea los posibles problemas que pueden llegar a enfrentar.

Por último, la innovación y la creatividad son factores esenciales para el funcionamiento y el adecuado manejo administrativo de una organización, ya que complementan y soportan cada una de las funciones del proceso administrativo; logrando que las empresas se adecuen a las necesidades del entorno, siendo eficientes y eficaces. Por ello, se puede inferir que la contabilidad no es la única forma de determinar el éxito o fracaso de una empresa, mediante utilidades 0 pérdidas, ya que para lograr estas últimas, se necesita de una buena administración, la cual debe entender todo el contexto, permitiendo lograr llevar a cabo planes y estrategias acordes a las realidades económicas de cada empresa. 


\section{REFERENCIAS:}

Baumol William, O. W. (1971). The use of standards and proce for protection of the environment. Swedish Journal of Economics.

Cruz, G., \& Uribe, E. (2002). El Efecto del Regulador y de la Comunidad sobre el Desempeño Ambiental dela Industria en Bogotá. Bogotá: CEDE.

Decreto N. 1594. Presidencia de la Republica de Colombia, 26 de junio de 1984

Decreto N. 901 Diario Oficial de la Republica de Colombia, 4 de abril de 1997

Fonseca, C. (3 de Julio de 2014). http://kalathos.metro.inter.edu/archivo.asp?ano=2 014. Recuperado el 22 de Octubre de 2014, de http://kalathos.metro.inter.edu/Num_13/Simon\%2 Opara\%20revista\%20kalatos.pdf

Frantz, R. (2003). http://bi.snu.ac.kr/. Recuperado el 15 de 12 de 2014, de http://bi.snu.ac.kr/Courses/4ai10f/Papers/Frantz\% $202003 \% 20$ -

\%20Herbert\%20Simon.\%20Artificial\%20intelligen ce\%20as \%20a\%20framework\%20for\%20underst anding\%20intuition.pdf

Gallopín, G. (Mayo de 2003). CEPAL. Recuperado el 14 de 08 de 2015, de http://repositorio.cepal.org/bitstream/handle/1136 2/5763/S033120_es.pdf?sequence=1

González, N. (2000). ¿El consenso sobre la racionalidad económica? Estudios Gerenciales, 76, 49-60.

Kolstad, C. D. (2000). Economia Ambiental . México D.F: Oxford University Press.

Kreps, D. (1988). Notes On The Theory Of Choice. México D.F: Oxford University Press.

Mejía, I. M. (Diciembre de 2010). REPOSITORIO ELECTRÓNICO DEL INSTITUTO POLITÉCNICO NACIONAL. Recuperado el 01 de Febrero de 2015, de http:/tesis.ipn.mx:8080/xmlui/handle/123456789/ 14236
Méndez, J. (Noviembre de 2008). Adaptación de algoritmos Genéticos para la Simulación del Comportamiento Estratégicode los Agentes Contaminantes ante el Cobro de Tasas Retributivas. Cuadernos de Administración, 35161-187.

Méndez, J., \& Hernandez, H. (2012). La Racionalidad Limitada de los Agentes Contaminadores y sus efectos sobre la eficiencia económica en el control de Vertimientos:caso de las tasas retributivas. Producción + Limpia, 32-47.

Romero, C. (1997). Economia de los Recursos Ambientales y Naturales. Alianza.

Rubinstein, A. (1998). Modeling Bounded Rationality. Cambrige Massachussetts: MIT Press.

Rudas, G. (Julio de 2006). CEPAL. Recuperado el 14 de Mayo de 2015, de CEPAL: http://www.cepal.org/ilpes/noticias/paginas/6/405 06/7_rudas_2006_contaminacion_riobogota.pdf

Simon, H. A. (1955). A Behavioral Model of Rational Choice. The Quarterly Journal Economics, 69(1), 99-118.

Streb, J. (Noviembre de 1998). https://www.ucema.edu.ar/publicaciones/doc_trab ajo.php/163\#tablestart. Recuperado el 15 de 10 de 2014, de https://www.ucema.edu.ar/publicaciones/downloa d/documentos/139.pdf

Velásquez, C. J. (2002). Financiación de la Gestión Ambiental en Colombia: el caso de las tasas retributivas. revista de derecho, universidad del norte, 151-171. 